This is the peer reviewed version of the following article: The health-related quality of life of patients with prostate cancer and their spouses before treatment compared with the general population. International Journal of Nursing Practice. 2017. Vol. 23, no.5, e12572. It has been published in final form at http://dx.doi.org/10.1111/ijn.12572.

This document has been downloaded from TamPub.uta.fi The Institutional Repository of University of Tampere

\title{
The Health-Related Quality of Life of Patients with Prostate Cancer and Their Spouses before Treatment Compared with the General Population
}

Eeva HARJU, MNSc, RN (correspondence)

Doctoral Candidate

Faculty of Social Sciences, Nursing Science, University of Tampere, Finland

Email address: eeva.j.harju@uta.fi

postal address: Arvo, FI-33014 University of Tampere, Finland

telephone number: +358503187632

Anja RANTANEN, PhD, RN

Docent, University Teacher

Faculty of Social Sciences, Nursing Science, University of Tampere, Finland

Email address: Anja.Rantanen@uta.fi

Postal address: Arvo, FI-33014 University of Tampere, Finland

Telephone number: +358401901452 
Marja KAUNONEN, PhD, RN

Professor

Faculty of Social Sciences, Nursing Science, University of Tampere, Finland

Email address: Marja.Kaunonen@uta.fi

Postal address: Arvo, FI-33014 University of Tampere, Finland

Telephone number: +358401901454

Department of General Administration, Pirkanmaa Hospital District, Finland

Postal address: PO Box 2000, FI-33521 Tampere University Hospital, Finland

Mika HELMINEN, MSc

Biostatistician

Faculty of Social Science, University of Tampere, Finland

Email address: Mika.Helminen@uta.fi

Postal address: Arvo, FI-33014 University of Tampere, Finland

Telephone number: +358401901599

Science Centre, Pirkanmaa Hospital District, Finland

Postal address: PO Box 2000, FI-33521 Tampere University Hospital, Finland

Taina ISOTALO, M.D., PhD

Chief Urologist

Department of Surgery, Päijät-Häme Central Hospital, Lahti, Finland

Email address: Taina.Isotalo@phsotey.fi

Postal address: Keskussairaalankatu 7, FI-15850 Lahti, Finland

Telephone number: +358381911 
Päivi ÅSTEDT-KURKI, PhD, RN

Professor

Faculty of Social Sciences, Nursing Science, University of Tampere, Finland

Postal address: Arvo, FI-33014 University of Tampere, Finland

Telephone number: +358505954516

Department of General Administration, Pirkanmaa Hospital District, Finland

Postal address: PO Box 2000, FI-33521 Tampere University Hospital, Finland

\title{
ACKNOWLEDGEMENTS
}

This study was supported by grants from the School of Health Sciences (University of Tampere), Finnish Association of Urological Nurses, Finnish Foundation of Urological Research and Nursing Foundation of the Pirkanmaa Hospital District.

\section{Authorship statement}

All listed authors meet the authorship criteria and they are in agreement with the content of the manuscript.

\begin{abstract}
Aims: To describe the health-related quality of life (HRQoL) of patients with prostate cancer and their spouses in comparison with the Finnish general population, using the RAND-36Item Health Survey. An additional purpose was to describe the associations between the background variables of the participants and their HRQoL.
\end{abstract}


Background: The HRQoL of patients with prostate cancer and especially their spouses at the time of diagnosis is not well known.

Design: A cross-sectional study.

Methods: Responses were received from 232 patients and 229 spouses at five central hospitals in Finland between October 2013 and January 2016.

Results: Compared to the Finnish general population mean, the HRQoL of the patients and their spouses was, on average, better for all dimensions. Patients' age, the presence of disease and the treatment method were associated with the dimensions of HRQoL. The dimensions of HRQoL were also associated with spouses' age, basic and vocational education and the presence of disease.

Conclusion: The patients and their spouses experienced their HRQoL as very similar; however, on average, it is better than the general population mean. However, the evidence suggests that support from the nurses should focus on emotional well-being, the dimension that received the lowest scores in both groups.

\section{SUMMARY STATEMENT}

\section{What is already known about this topic?}

- The incidence rates of prostate cancer have increased

- Prostate cancer and its treatments affect patients' quality of life.

- The HRQoL of spouses at the time of diagnosis is unclear in the literature.

\section{What this paper adds:}

- At the time of diagnosis, the HRQoL of the patients with prostate cancer and their spouses was better than the age- and gender-stratified Finnish population. 
- The HRQoL of the patients and their spouses did not differ from each other at the time of diagnosis.

- The demographic factors of spouses including age, basic education, vocational qualifications and chronic diseases were associated with spouses physical functioning, physical and emotional role functioning, bodily pain and general health.

\section{The implications of this paper:}

- Nurses should pay more attention to the emotional role functioning of spouses as part of good prostate cancer care.

- Nurses should particularly take into consideration the physical functioning of patients who are more than 70 years old, treated with hormone therapy and have an earlier disease.

- Nurses can develop and implement interventions based on knowledge about the HRQoL of these patients and their spouses.

Keywords: prostate cancer, quality of life, spouses 


\section{INTRODUCTION}

The incidence of prostate cancer has increased rapidly and an estimated 1.1 million men worldwide were diagnosed with prostate cancer in 2012 (Ferlay et al. 2015). Prostate cancer is presently the most common type of cancer among men in developed countries as well as in the Finnish men. More than 4700 Finnish men, who are mostly over 70 years of age, are diagnosed with prostate cancer each year (Engholm et al. 2015, Ferlay et al. 2015). Most Finnish men with prostate cancer live together with their spouses (Lehto et al. 2015). Therefore, prostate cancer in a family member affects the whole family. Together with the cancer symptoms, the side effects of treatment may lead to psychological distress and impaired functional capacity, reducing psychological well-being and quality of life (Northouse et al. 2007, Sanda et al. 2008, Harden et al. 2013b).

The most typical symptoms caused by active treatment of prostate cancer are urine incontinence and sexual problems. In addition, hormonal treatment may cause physical and psychological symptoms. Because the symptoms are deeply personal matters, they may cause psychological and social problems that might not be recognized (Sanda et al. 2008, Roth et al. 2008, Huang et al. 2010, Mc Caughan et al. 2013, Lehto et al. 2015). Mutual psychological distress of patients with prostate cancer and their spouses can lead to a poor quality of life (Kim et al. 2008). The absence of a spouse appears to be a risk factor for poor quality of life in men on active surveillance (Bellardita et al. 2014). Single men reported a lower quality of life one year post treatment than married men (Dieperink et al. 2012, Mc Caughan et al. 2013). On the other hand, marital discord can also weaken HRQOL of patients with prostate cancer (Merz et al. 2011). 


\section{Health-related quality of life}

The concept of quality of life has become significant in relation to health because there are an increasing numbers of individuals living with long-term illnesses (Eton \& Lepore 2002). The quality of life represents an individual's idea of his or her situation in life in that set of values and in the cultural context in which the person lives (The WHOQOL Group, 1998). Quality of life includes an individual's physical health, psychological functioning, degree of the independence, social relations and his /her relation with the environment (The WHOQOL Group, 1998). HRQoL is specified in this study, which includes individuals' physical, psychological and social ability to function and welfare and it is dealt with from the points of view of prostate cancer patients and of their spouses (Aalto et al. 1999, Bowling 2004). It has been stated that prostate cancer and its treatments will affect the patients' as well as the spouses' quality of life (Maliski et al. 2002, Sanders et al. 2006, Harden et al. 2008, Kim et al. 2008).

Combined treatments and use of medication have been associated with worse physical and role functioning among patients with prostate cancer (Green et al. 2011). Ratings for physical and social functioning are the highest among the subscales for HRQoL before treatment (Green et al. 2011, Vasarainen et al. 2013, Paterson et al. 2015), while global quality of life / general health and vitality are the weakest subscales (Green et al. 2011, Vasarainen et al. 2013, Cary et al. 2014). Three months following the prostate cancer treatment, patients reported that physical functioning, energy and general health were lower when compared to other items on a generic HRQoL scale. They had been treated for radical prostatectomy, radiation therapy, hormonal therapy or watchful waiting. Among prostate-specific HRQoL subscales, sexual function and sexual scores are lower compared with other scales (Jayadevappa et al. 2012). Patients with prostate cancer are more worried about their sexual 
disability than their spouses (Burt et al. 2005, Couper et al. 2006, Merz et al. 2011).

Furthermore, when compared to the general population, the HRQoL of patients with prostate cancer remained at a relatively high level as long as the cancer remains localized (Torvinen et al. 2013). Impotence, loss of libido, incontinence and fatigue resulting from treatment affect the lives of both patients and their spouses and can reduce the quality of life of both (Navon \& Morag 2003, War-Smith \& Kapitan 2005, Yang et al. 2005). At the time of the prostate cancer diagnosis, little is known about the spouses' quality of life. Patients' and their spouses' quality of life is reported more after the primary treatment of prostate cancer.

In previous studies, factors related to the socioeconomic background of patients with prostate cancer, such as income and education have been related to HRQoL. Patients with low socioeconomic background have reported low HRQoL as well. Therefore, they are in greater need of guidance from the nurses (Penson et al. 2001, Rayford 2006). In addition to age and symptoms, financial difficulties seemed to be the most important determinant related to the poor HRQoL of patients with prostate cancer (Torvinen et al. 2013). However, the connection between patients' socioeconomic background and quality of life is not necessarily this unambiguous (Maliski et al. 2011). According to a cross-sectional study (Green et al. 2011), high education is associated with better role functioning and reduced fatigue.

Spouses' younger age and lower income have been associated with greater distress and poorer quality of life (Deimling et al. 2002, Harden et al. 2013b, Wu \& Harden 2015). Likewise, spouses who have low education reported distress regarding their husbands' prostate cancer (Eton \& Lepore 2002). Spouses expressed ongoing worries about their husbands' illness those worries were associated with their sense of well-being and sleep, which may then affect the spouses' appraisals of their husbands' illness and in turn the spouses' own quality of life 
(Harden et al. 2006). After prostate cancer treatment problems related to the changes in the sexual relationship were reported more by spouses than patients (Harden et al. 2008). The spouses try to retain emotional balance and try to maintain a positive attitude because they are the most important support for the patient. At the same time, spouses reported patients' social functioning as significantly better and emotional functioning as significantly worse than the patients' own ratings (Green et al. 2011).

Although, the number of patients with prostate cancer has increased steadily during the last two decades, there is little knowledge of patients' and spouses' HRQoL before the start of cancer treatment. There is also a lack of knowledge on the ways in which their HRQoL differs from that of the general population. This knowledge is needed for the further development of nursing of patients with prostate cancer and their family.

\section{METHODS}

\section{Aims}

The aim of this study was to examine the HRQoL of patients with prostate cancer and their spouses before treatment of prostate cancer in comparison with the general population. Furthermore, this study investigated the demographic variables associated with the HRQoL in patients with prostate cancer and their spouses.

\section{Design}

This cross-sectional study is a part of a longitudinal study. Data were collected from newly diagnosed patients with prostate cancer and their spouses before the start of prostate cancer treatment. 


\section{Participants}

The study sample consisted of 350 consecutive new patients with prostate cancer and their spouses regardless of the prospective treatment of prostate cancer. The inclusion criterion was men diagnosed with prostate cancer, prior to the beginning of treatment. Men characterized the relationship to their spouse as permanent and provided written informed consent with the additional contact information for their spouse. The enrolled patients received questionnaire forms for both themselves and their spouses, with a return envelope, during their appointment with a nurse. The completed questionnaires were mailed to the researcher's office. If neither the patient nor the spouse returned the questionnaire, they did not receive the follow-up questionnaire.

The sample size was calculated together with a statistician. In previous studies (Osoba et al. 2005), clinically significant change in health-related quality of life scores was determined at 10 points. The sample size calculation was based on paired-samples t-test. Using a standard deviation of 20 , with the alpha value set at 0.05 and the power at 0.8 , a change of 10 points was calculated to be statistically significant with a sample of 33 respondents (Osoba et al. 2005). Assuming that approximately half of the participants would complete the survey, the figure was rounded to 70 patients. In addition, the patients might receive at least four types of treatment, in five different hospitals. Thus, the questionnaire was distributed to 350 patients and their spouses $(\mathrm{N}=350)$.

\section{Data collection}

Recruitment was done at the urology clinics of five Finnish central hospitals between October 2013 and January 2016. In the participating hospitals, altogether 800-900 new patients with prostate cancer are being treated every year. 
RAND-36 - Item Health Survey

The Finnish version of the RAND-36-Item Health Survey (RAND-36) was used to measure both patients and spouses' perspectives on HRQoL. The RAND-36 utilizes exactly the same questions as the Medical Outcome Study SF-36 (MOS SF-36); however, the scoring of general health and bodily pain does differ slightly for the MOS SF-36 (Ware \& Sherbourne 1992, Hays et al. 1993). The RAND-36 consists of a total of 36 items divided into eight subscales: physical functioning, bodily pain, role limitations due to emotional/physical problems, emotional well-being, social functioning, energy/fatigue and general health perceptions (Aalto et al. 1999). Each subscale with higher scores indicates better corresponding HRQoL domain (Ware \& Sherbourne 1992). The RAND-36 is an internationally used instrument in measuring the HRQoL of patients with prostate cancer and their spouses (Treiyer et al. 2011, Dieperink et al. 2012b, Vasarainen et al. 2013, Harden et al. 2013a, Cary et al. 2014). In international surveys on patients with prostate cancer, the coefficients have been over 0.88 (Harden et al. 2013). The reliability of the instrument has been tested in Finland, with Cronbach's alpha coefficients for internal consistency at 0.80 0.94 (Aalto et al. 1999). To allow comparison with the general population, age-stratified reference values for the subscales have been established (Aalto et al. 1999, Vasarainen et al. 2013). The samples of the general population were randomly selected from the Finnish Population Register. The response rate was $64 \%(n=2175)$ (Aalto et al. 1999).

\section{Demographic characteristics}

The demographic characteristics of participants included age, duration of the marital relationship, basic and vocational education, employment status and chronic diseases. In 
addition, among the patients' demographic characteristics were the hospital where the prostate cancer was diagnosed and treated and the treatment methods for the cancer.

\section{Ethical considerations}

The ethicality of this study was approved by the Scientific Committee of the local hospital district. The directors of the five participating hospitals permitted its execution. All respondents were informed in writing and orally of the purpose of the study and of the principle of voluntary, anonymous participation.

\section{Data analysis}

Standard methods were used for the descriptive statistics mean and standard deviation. The quality of life subscales of the RAND-36 were scored in two phases. First, the numeric values given in the questionnaire were recoded according to the scoring instructions of the

instrument. Second, summated variables of the eight subscales were formed from the indices. All eight subscales are separately scored from 0 to 100, with higher scores indicating better HRQoL (Aalto et al. 1999). All eight dimensions did not meet the assumption of normality, using the Spearman's rank correlation, Wilcoxon Signed Ranks, Mann-Whitney, and KruskalWallis tests to examine associations. These were followed by post hoc comparisons using Bonferroni adjustment to determine where the change occurred. The internal consistency of the summated variables was tested using Cronbach's alpha coefficients (Burns \& Grove 2009). All analyses were carried out using IBM SPSS statistics Version 23 (IBM Corp., Armonk, NY, USA). The level of statistical significance was set at $\mathrm{p}<0.05$. 


\section{RESULTS}

\section{Demographic characteristics of respondents}

Responses were received from 232 patients and 229 spouses. The overall response rate was $65 \%$. The mean age of the patients with prostate cancer was 68 years $(\mathrm{SD}=8.4)$, ranging from 40 to 86 years (Table 1). The marital relationship of the participants was an average of 36 years $(\mathrm{SD}=16.0)$. The shortest marital relationship was less than one year and the longest was 61 years. More than two-thirds of the patients with prostate cancer had completed elementary school or civic school and more than half were not working. More than one-third of the patients had no other disease in addition to prostate cancer. The prostate cancer of one-third of the patients would initially be treated by surveillance, i.e. the patient would receive noninvasive care.

The ages of the spouses ranged from 33 to 85 , with a mean age of 65 years $(\mathrm{SD}=9.0)$. Nearly half of the spouses had completed either elementary school or civic school. One-fourth of the spouses had no vocational qualification and half of them were not working. More than twothirds of the spouses had a chronic disease (cardiovascular diseases, diabetes, chronic lung disease and musculoskeletal disorders) (Table 1).

\section{Health-related quality of life}

Based on the average value, the HRQoL of the patients with prostate cancer and their spouses was best on the dimensions of social and physical functioning (Table 2). Compared to the age- and gender-stratified Finnish population mean, HRQoL of the patients with prostate cancer was on average better on all dimensions. The difference between the means was statistically significant on all dimensions of HRQoL. Spouses' HRQoL was on average better 
on all eight dimensions compared to the age- and gender-stratified mean Finnish population. The difference between the means was statistically significant. Correspondingly, the association between the means of patients and spouses was not statistically significant. The correlation between the HRQoL of patients and their spouses was weak $(r=0.08-0.22)$.

Association between demographic characteristics of the patients with prostate cancer and their HRQoL (RAND-36)

An association was detected between the age, the presence of another disease and the treatment method of the patients with prostate cancer and their HRQoL (Table 3.). Patients who were 60 - 69 years old reported higher satisfaction with physical functioning and physical role functioning than those over 70 . Patients with prostate cancer who also have the presence of other disease reported that their perceived physical role functioning and general health was lower than those patients who had no other diseases. An association was detected between the treatment method for prostate cancer and the dimension of perceived general health. Patients who receive surgical treatment perceived their general health to be better than those who would receive hormonal treatment. There was no evidence of an association between the HRQoL and basic education, vocational qualification, employment status or duration of the marital relationship.

Association between the spouses' demographic characteristics and their HRQoL (RAND-36)

The associations between the demographic characteristics of the spouses and their HRQoL are presented in Table 4. Their age was associated with physical functioning, physical and emotional role functioning and general health. Spouses who were younger than 60 years old reported higher satisfaction with physical functioning, physical role functioning and general health than those 70 or over. Spouses who were 60-69 years of age reported higher 
satisfaction with emotional role functioning than those 70 or over. Their level of basic education was associated with general health. Those who had completed higher secondary education perceived their general health as better than those who had completed only elementary or civic school. Similarly, spouses who had a polytechnic or university degree perceived their health as better than those without a vocational qualification. Those who had no chronic disease perceived their physical functioning, physical role functioning, bodily painlessness and general health better than those who had a chronic disease. Neither employment status nor the duration of the marital relationship was associated with the HRQoL of the spouses.

\section{DISCUSSION}

\section{Health-related of quality of life}

The main finding of this study was that the HRQoL of the patients with prostate cancer and their spouses was, on average, better on all dimensions when compared to the age- and gender-stratified Finnish population mean. Patients experienced better HRQoL compared to the age- and gender-stratified Finnish population mean on all eight dimensions. The findings lend support to past studies that have quantified the short-term impact of the prostate-specific antigen (PSA) screening process on the HRQoL (Vasarainen et al. 2013). In addition, with other instruments of HRQoL, parallel results have been obtained from Finnish patients with prostate cancer treated with radiotherapy, hormone therapy or palliative. As long as the disease remained localized, patients' HRQoL remained at a relatively high level (Torvinen et al. 2013). Previous studies have showed that the quality of life of patients with prostate cancer treated with either surgery or radiation therapy was lower compared to the quality of life for the general population (Sanda et al. 2008, Mols et al. 2009). 
The spouses in the present study experienced better HRQoL on all eight dimensions than the age- and gender-stratified Finnish population mean. Similar results have been found in other studies of partners of the patients with prostate cancer after treatment (Harden et al. 2013b). Potential changes in the quality of life might come forth in longitudinal studies of patients with prostate cancer and their spouses. Previous longitudinal studies have identified that spouses' quality of life is associated with their spouses' patient treatments for prostate cancer, especially if these patients report many side effects of their treatment (Green et al. 2011, Harden et al. 2013a). Our findings show that patients experienced mildly higher physical functioning, emotional well-being and painlessness than spouses. On the other hand, spouses experienced higher physical role functioning than patients. An earlier study has shown that there is a connection between social support and quality of life of patients with prostate cancer (Queenan et al. 2010). Perhaps this partly explains why in this study quality of life the patients with prostate cancer was relatively high compared to the age- and gender-stratified Finnish population mean. Our study group included patients with prostate cancer who have the relationship to their spouses as permanent, which could, at least in part, explain the difference in the HRQoL between the reference populations. It may also be possible that, on average, healthier men and their spouses than patients with prostate cancer and their spouses usually may have participated in this survey.

\section{The characteristics of patients with prostate cancer}

The findings suggest that age, other diseases and the treatment method of patients with prostate cancer were associated with the HRQoL. Younger patients rated these dimensions of the quality of life better than older patients. The similar findings have been reported to the patient's age from the effects of the health (Harju et al. 2012). Further, physical health 
supposedly diminishes with age, which may be seen in the results of this study. On the other hand, previous studies have indicated that a younger age was associated with a poorer quality of life (Deimling et al. 2002, Harden et al. 2008, Wu \& Harden 2015). In the patient data, chronic diseases were associated with physical functioning and also general health. In this study, the planned treatment method for prostate cancer was associated with general health. Patients who would receive hormonal treatment perceived their general health to be poorer than those who would receive surgical treatment. According to prostate cancer guidelines (Heidenreich et al. 2011) the HRQoL of patients with prostate cancer plays an important role in the choice of patient treatment option. The hormonal treatment will also be the primary alternative for the treatment of metastasized prostate cancer and for those patients where local radical treatment is not an option. The choice of treatment, thus, depends on the prostate cancer patient's general condition and the patient's age. (Heidenreich et al. 2011.)

\section{The characteristics of spouses}

Spouses who were younger than 60 years rated their physical functioning, physical and emotional role functioning and general health better than older spouses. The findings differ from those of a previous study (Wu \& Harden 2015). However, patients who have other cancers than prostate cancer and their spouses also participated in Wu \& Harden (2015) study. Other findings from a longitudinal study (Harden et al. 2013b) indicate that spouses who were younger than 65 years, perceived more threat and stress in their caregiving role, experienced more disturbance by their husbands' post-treatment symptoms. In this study spouses who had higher basic education or vocational qualifications rated their general health better than those who had lower basic education or no vocational qualifications. This is consistent with the results of other studies (Eton \& Lepore 2002). In the patient data of this study, a similar significant association was not found. One explanation could be gender differences because 
the women and men may experience and rate their quality of life differently. The chronic diseases of spouses were associated with weaker physical functioning, physical role functioning, bodily painlessness and general health. These results are consistent because chronic diseases are likely to just affect the physical dimensions of HRQoL.

The study has some limitations. The patients with prostate cancer included patients with different tumour stages and were not asked to report on characteristics such as stage, grade or disease status. On the other hand, the patients' cancer treatments had not begun yet. The patients were not asked to describe their first symptom of prostate cancer. They were diagnosed with prostate cancer on the basis of the screening or the symptoms. This can have an effect on patients' perceived quality of life. Potential first symptoms of the prostatic cancer can already affect patients' HRQoL. Only patients with prostate cancer who characterized their relationship with their spouse as permanent were included in the study. This means that the results cannot be extrapolated to all patients with prostate cancer.

In this study, Cronbach's alpha coefficients for RAND-36 scales ranged from $0.85-0.87$ in the patient and from $0.82-0.84$ in the spouse data, demonstrating good internal consistency (Burns \& Grove 2009). The representativeness of the sample is supported by the good response rate $(65 \%)$. The sample still is fairly small and selective. The confounding factors such as family relationships or economic factors may also affect the results. Factors other than merely prostate cancer may have affected the HRQoL of the patients and their spouses. Although participants were asked to complete questionnaires separately, it is still possible that some couples discussed the questionnaire items together. Spouses were not asked to identify their gender, so in the analyses attention was not paid to same or separate sex couples. Selfreported data on treatment are limited by patients' understanding and recall of treatments. 
Overall, the findings support previous research regarding giving consideration to both patients' and their spouses' quality of life in both research and clinical practice.

\section{CONCLUSION}

In summary, in this study, patients with prostate cancer who characterized the relationship with their spouse as permanent experienced their HRQoL as relatively good compared with the general population. Their counselling and support should thus focus on emotional wellbeing, because this dimension was found to be closest to the age- and gender-stratified population mean. The results further added nurses' knowledge of the HRQoL on the patients with prostate cancer and their spouses. Counselling and support of patients with prostate cancer should be more family-focused and focus on emotional well-being, because this dimension was found to be the closest to the age- and gender-stratified population mean for both the patients and their spouses. In addition, nurses should pay more attention to couples older than 70 years who have other chronic diseases or receive hormonal treatment. It is important that at the time of diagnosis, all spouses will be considered and noticed for counseling, support and advise because spouses are important supporters of those patients with prostate cancer.

Further longitudinal follow-up studies are still essential to identify the changes in the HRQoL and any related factors that are affecting patients and their spouses during and after prostate cancer treatment. Based on this information, timely interventions can then be developed to support patients with prostate cancer and their spouses. Also, it is important to recognize those couples with low HRQoL and focus these interventions on them. 


\section{DISCLOSURE}

The authors declare no conflict of interest. 


\section{REFERENCES}

Aalto, A. , Aro, A. R. , \& Teperi, J. (1999). RAND-36 as a measure of Health-Related Quality of Life. Reliability, construct validity and reference values in the Finnish general population. Stakes, Research Reports 101, Helsinki.

Bellardita, L. , Villa, S. , \& Valdagni R. (2014). Living with untreated prostate cancer: predictors of quality of life. Current Opinion in Urology, 24, 311-317. doi: 10.1097/MOU.0000000000000038

Bowling, A. (2004). Measuring health: a review of quality of life measurement scales. Open University Press, Maidenhead.

Burns, N. \& Grove, S.,K. (2009). The Practice of Nursing Research: Appraisal, Synthesis, and Generation of Evidence, $6^{\text {th }}$ ed.). Elsevier Saunders, USA.

Burt, J. , Caelli, K. , Moore, K. , \& Anderson, M. (2005), Radical prostatectomy: men's experiences and postoperative needs. Journal of Clinical Nursing, 14, 883-890. doi: 10.1111/j.1365-2702.2005.01123.x

Cary, K. , Singla, N. , Cowan, J. , Carroll, P. , \& Cooperberg, M. (2014). Impact of androgen deprivation therapy on mental and emotional well-being in men with prostate cancer: analysis from the CaPSURETM registry. Journal of Urology, 191, 964-970. doi: org/10.1016/j.juro.2013.10.098

Couper, J., Bloch, S. , Love, A., Macvean, M. , Duchesne, G. M. , \& Kissane, D. (2006). Psychosocial adjustment of female partners of men with prostate cancer: a review of the literature. Psycho-Oncology, 15, 937-953. doi: 10.1002/pon.1031

Deimling, G. T. , Kahana, B. , Bowman, K. F. \& Schaefer, M. L. (2002). Cancer survivorship and psychological distress in later life. Psycho-Oncology, 11, 479-494. doi: 10.1002/pon.614

Dieperink, K. B., Hansen, S., Wagner, L., Johansen, C., Andersen, K. K. , \& Hansen, O. (2012). Living alone, obesity and smoking: Important factors for quality of life after radiotherapy and androgen deprivation therapy for prostate cancer. Acta Oncologica, 51, 722-729. doi: 10.3109/0284186X.2012.682627

Engholm, G., Ferlay, J., Christensen, N., Kejs, A.M.T., Hertzum-Larsen, R., Johannesen, T.B., ... Storm, H.H. (2015) NORDCAN: Cancer incidence, mortality, prevalence and survival in the Nordic countries, Version 7.3. (08.07.2016) Association of Nordic Cancer Registries. Danish Cancer Society. Available at: http://www.ancr.nu/ (accessed 04.06.17).

Eton, D. T. , \& Lepore, S. J. , (2002). Prostate cancer and health-related quality of life: a review of the literature. Psycho-Oncology, 11, 307-326. doi: 10.1002/pon.572 
Ferlay, J. , Soerjomataram, I. , Ervik, M. , Dikshit, R. , Eser, S. , Mathers, C. , Rebelo, M. , Parkin, D. , Forman, D. , \& Bray, F. (2015). GLOBOCAN 2012 v1.0, Cancer Incidence and Mortality Worldwide: IARC CancerBase No. 11 Lyon, France: International Agency for Research on Cancer; 2013. Available at: http://globocan.iarc.fr (accessed 31.08.15).

Green, H. , Wells, D. , \& Laakso, L. (2011). Coping in men with prostate cancer and their partners: a quantitative and qualitative study. European Journal of Cancer Care, 20, 237247. doi: 10.1111/j.1365-2354.2010.01225.x

Harden, J. , Northouse, L. , Cimprich, B. , Pohl, J. M. , Liang, J. , \& Kershaw, T. (2008). The influence of developmental life stage on quality of life in survivors of prostate cancer and their partners. Journal of Cancer Survivorship, 2, 84-94. doi: 10.1007/s11764-008-0048$\mathrm{z}$

Harden, J. , Sanda, M. , G. , Wei, J. T. , Yarandi, H. N. , Hembroff, L. , Hardy, J. , \& Northouse, L. (2013a). Survivorship after prostate cancer treatment: spouses' quality of life at 36 months. Oncology Nursing Forum 40, 567-573. doi: 10.1188/13.ONF.567-573

Harden, J. , Sanda, M. , Wei, J. , Yarandi, H. , Hembroff, L. , Hardy, J. , Northouse, L. , \& PROSTQA Consortium Study Group. (2013b). Partners' long-term appraisal of their caregiving experience, marital satisfaction, sexual satisfaction, and quality of life 2 years after prostate cancer treatment. Cancer Nursing, 36, 104-113. doi: 10.1097/NCC.0b013e3182567c03

Harden, J. K. , Northouse, L. L. , \& Mood, D. W. (2006). Qualitative analysis of couples' experience with prostate cancer by age cohort. Cancer Nursing, 29, 367-377. doi: 10.1097/00002820-200609000-00004

Harju, E. , Rantanen, A. , Tarkka, M. , \& Åstedt-Kurki, P. (2012). Perceived family health in persons with prostate cancer and their family members. Journal of Clinical Nursing, 21, 544-554. doi: 10.1111/j.1365-2702.2011.03775.x

Hays, R. , Sherbourne, C. , \& Mazel, R. (1993). The RAND 36-item health survey 1.0. Health Economics, 2, 217-227.

Heidenreich, A. , Bellmunt, J. , Bolla, M. , Joniau, S. , Mason, M. , Matveev, V. , Mottet, N. , Schmid, H. , van der Kwast, T. , Wiegel, T. , \& Zattoni, F. (2011). EAU guidelines on prostate cancer. part 1: screening, diagnosis, and treatment of clinically localised disease. European Urology, 59, 61-71. doi: 10.1016/j.eururo.2010.10.039

Huang, G. J. , Sadetsky, N. , \& Penson, D. F. (2010). Health related quality of life for men treated for localized prostate cancer with long-term followup. Journal of Urology, 183, 2206-2212. doi: 10.1016/j.juro.2010.02.013

Jayadevappa, R., Malkowicz, S. B. , Wittink, M., Wein, A. J. \& Chhatre, S. (2012). Comparison of distribution- and anchor-based approaches to infer changes in healthrelated quality of life of prostate cancer survivors. Health Services Research, 47, 19021925. doi: 10.1111/j.1475-6773.2012.01395.x 
Kim, Y. , Kashy, D. A., Wellisch, D. K., Spillers, R. L. , Kaw, C. K. , \& Smith, T.G. (2008). Quality of life of couples dealing with cancer: dyadic and individual adjustment among breast and prostate cancer survivors and their spousal caregivers. Annals of Behavioral Medicine, 35, 230-238. doi: 10.1007/s12160-008-9026-y

Lehto, U., Helander, S. , Taari, K. , \& Aromaa, A. (2015). Patient experiences at diagnosis and psychological well-being in prostate cancer: A Finnish national survey. European Journal of Oncology Nursing, 19, 220-229. doi: 10.1016/j.ejon.2014.10.018

Maliski, S. L. , Heilemann, M. V. , \& McCorkle, R. (2002). From "death sentence" to "good cancer": couples' transformation of a prostate cancer diagnosis. Nursing Research, 51, 391-397. doi: 10.1097/00006199-200211000-00007

Maliski, S. L., Connor, S. E. , Oduro, C. , \& Litwin, M. S. (2011). Access to health care and quality of life for underserved men with prostate cancer. Seminars in Oncology Nursing, 27, 267-277. doi: 10.1016/j.soncn.2011.07.005

Mc Caughan, E. , Mc Sorley, O. , Prue, G. , Parahoo, K. , Bunting, B. , Sullivan, J. O. , \& Mckenna, H. (2013). Quality of life in men receiving radiotherapy and neo-adjuvant androgen deprivation for prostate cancer: results from a prospective longitudinal study. Journal of Advanced Nursing, 69, 53-65. doi: 10.1111/j.1365-2648.2012.05987.x

Merz, E. L. , Malcarne, V. L. , Ko, C. M. , Sadler, M. , Kwack, L. , Varni, J. W. , \& Sadler, G. R. (2011). Dyadic concordance among prostate cancer patients and their partners and health-related quality of life: Does it matter? Psychology \& Health, 26, 651-666. doi: 10.1080/08870441003721251

Mols, F. , Korfage, I. J. , Vingerhoets, A. J. J. M. , Kil, P. J. M. , Coebergh, J. W. W. , EssinkBot, M. , \& van de Poll-Franse, L. V. (2009). Bowel, urinary, and sexual problems among long-term prostate cancer survivors: a population-based study. International Journal of Radiation Oncology*Biology*Physics, 73, 30-38. doi:

10.1016/j.ijrobp.2008.04.004

Navon, L. , \& Morag, A. (2003). Advanced prostate cancer patients' ways of coping with the hormonal therapy's effect on body, sexuality, and spousal ties. Qualitative Health Research, 13, 1378-1392. doi: 10.1177/1049732303258016

Northouse, L. L. , Mood, D. W. , Montie, J. E. , Sandler, H. M. , Forman, J. D. , Hussain, M. , Pienta, K. J. , Smith, D. C. , Sanda, M. G. , \& Kershaw, T. (2007). Living with prostate cancer: patients' and spouses' psychosocial status and quality of life. Journal of Clinical Oncology, 25, 4171-4177. doi: 10.1200/JCO.2006.09.6503

Osoba, D. , Bezjak, A. , Brundage, M. , Zee, B. , Tu, D., Pater, J. , \& Quality of Life Committee of the NCIC CTG, (2005). Analysis and interpretation of health-related quality-of-life data from clinical trials: basic approach of The National Cancer Institute of Canada Clinical Trials Group. European Journal of Cancer, 41, 280-287. doi: 10.1016/j.ejca.2004.10.017 
Paterson, C. , Robertson, A. , Smith, A. , \& Nabi, G. (2015). Identifying the unmet supportive care needs of men living with and beyond prostate cancer: a systematic review. European Journal of Oncology Nursing, 19, 405-418. doi: 10.1016/j.ejon.2014.12.007

Penson, D. F. , Stoddard, M. L., Pasta, D. J. , Lubeck, D. P., Flanders, S. C. , \& Litwin, M. S. (2001). The association between socioeconomic status, health insurance coverage, and quality of life in men with prostate cancer. Journal of Clinical Epidemiology, 54, 350358. doi: 10.1016/S0895-4356(00)00312-7

Queenan, J. , Feldman-Stewart, D. , Brundage, M. , \& Groome, P. (2010). Social support and quality of life of prostate cancer patients after radiotherapy treatment. European Journal of Cancer Care, 19, 251-259. doi: 10.1111/j.1365-2354.2008.01029.x

Rayford, W. 2006. Managing the low-socioeconomic-status prostate cancer patient. Journal of the National Medical Association, 98, 521-530.

Roth, A. J. , Weinberger, M. I. , \& Nelson, C. J. (2008). Prostate cancer: psychosocial implications and management. Future Oncology, 4, 561-568.

Sanda, M. G. , Dunn, R. L., Michalski, J. , Sandler, H. M. , Northouse, L. , Hembroff, L. , Lin, X. , Greenfield, T. K. , Litwin, M. S. , Saigal, C. S. , Mahadevan, A. , Klein, E. , Kibel, A. , Pisters, L. L. , Kuban, D. , Kaplan, I. , Wood, D. , Ciezki, J. , Shah, N. , \& Wei, J. T. (2008). Quality of life and satisfaction with outcome among prostate-cancer survivors. New England Journal of Medicine, 358, 1250-1261. doi: 10.1056/NEJMoa074311

Sanders, S. , Pedro, L. W. , Bantum, E. O. , \& Galbraith, M. E. (2006). Couples surviving prostate cancer: long-term intimacy needs and concerns following treatment. Clinical Journal of Oncology Nursing, 10, 503-508. doi: 10.1188/06.CJON.503-508

The WHOQOL Group. , (1998). Development of the World Health Organization WHOQOLBREF. Quality of Life Assessment. Psychological Medicine, 3, 551-558. doi: $10.1017 /$ S0033291798006667

Torvinen, S. , Färkkil, N. , Sintonen, H. , Saarto, T. , Roine, R. P. , \& Taari, K. (2013). Health-related quality of life in prostate cancer. Acta Oncologica, 52, 1094-1101. doi: 10.3109/0284186X.2012.760848

Treiyer, A., Anheuser, P. , Butow, Z. , \& Steffens, J. (2011). A single centre prospective study: prediction of postoperative general quality of life, potency and continence after radical retropubic prostatectomy. Journal of Urology, 185, 1681-1685. doi: 10.1016/j.juro.2010.12.052

Vasarainen, H. , Malmi, H. , Maattanen, L. , Ruutu, M. , Tammela, T. , Taari, K. , Rannikko, A. , \& Auvinen, A. (2013). Effects of prostate cancer screening on health-related quality of life: results of the Finnish arm of the European randomized screening trial (ERSPC). Acta Oncologica, 52, 1615-1621. doi: 10.3109/0284186X.2013.802837

Ware, J. E. J. , \& Sherbourne, C. D. (1992). The MOS 36-item short-form health survey (SF36): I. conceptual framework and item selection. Medical Care, 30, 473-483. 
War-Smith, P. , \& Kapitan, D. (2005). Quality of life among men treated with radiation therapy for prostate cancer. Urologic Nursing, 25, 263-268.

Wu, H. , \& Harden, J. K. (2015). Symptom burden and quality of life in survivorship: a review of the literature. Cancer Nursing, 38, E29-54. doi:

10.1097/NCC.0000000000000135

Yang, B. K. , Crisci, A., Young, M. D., Silverstein, A. D. , Peterson, B. L. , \& Dahm, P. (2005). Cross-sectional survey of long-term quality of life after radical perineal prostatectomy. Urology, 65, 120-125. doi: 10.1016/j.urology.2004.08.046 
Table 1 Demographic characteristics of patients with prostate cancer $(n=232)$ and their spouses $(n=229)$

\begin{tabular}{|c|c|c|c|c|c|}
\hline Variable & & $\begin{array}{c}\text { Patients } \\
\text { n }\end{array}$ & $\%$ & $\begin{array}{c}\text { Spouses } \\
n\end{array}$ & $\%$ \\
\hline \multicolumn{6}{|l|}{ Age years } \\
\hline & $\leq 59$ & 42 & 18 & 60 & 26 \\
\hline & $60-69$ & 98 & 42 & 104 & 46 \\
\hline & $\geq 70$ & 92 & 40 & 65 & 28 \\
\hline \multicolumn{6}{|c|}{ Duration of marital relationship (years) } \\
\hline & $\leq 25$ & 57 & 25 & & \\
\hline & $26-40$ & 58 & 25 & & \\
\hline & $\geq 41$ & 116 & 50 & & \\
\hline \multicolumn{6}{|c|}{ Basic education } \\
\hline & Elementary school/civic school & 148 & 64 & 108 & 47 \\
\hline & $\begin{array}{l}\text { Comprehensive school/lower } \\
\text { Secondary school }\end{array}$ & 49 & 21 & 61 & 27 \\
\hline & Upper secondary school & 35 & 15 & 60 & 26 \\
\hline \multicolumn{6}{|c|}{ Vocational qualifications } \\
\hline & Initial vocational qualification & 69 & 30 & 65 & 29 \\
\hline & Further vocational qualification & 59 & 26 & 71 & 32 \\
\hline & Polytechnic/university degree & 23 & 10 & 31 & 14 \\
\hline & No vocational qualification & 76 & 34 & 55 & 25 \\
\hline \multicolumn{6}{|c|}{ Employment status } \\
\hline & Working & 99 & 43 & 107 & 47 \\
\hline & Not working & 133 & 57 & 122 & 53 \\
\hline \multicolumn{6}{|c|}{ Chronic diseases } \\
\hline & Yes & 160 & 69 & 147 & 64 \\
\hline & No & 72 & 31 & 82 & 36 \\
\hline \multicolumn{6}{|c|}{ Treatment method } \\
\hline & Surgery & 62 & 27 & & \\
\hline & Radiation therapy & 32 & 14 & & \\
\hline & Hormonal treatment & 53 & 23 & & \\
\hline & Non-invasive care & 80 & 36 & & \\
\hline
\end{tabular}


Table 2. RAND 36-item health survey mean scores of the patients with prostate cancer $(n=232)$ and their spouses $(n=229)$

\begin{tabular}{|c|c|c|c|c|c|c|c|c|c|c|c|c|}
\hline $\begin{array}{l}\text { Quality of life } \\
\text { dimension }\end{array}$ & Items & Patients & SD & $\begin{array}{c}\text { RAND } \\
\text { average } \neq\end{array}$ & SD & $\begin{array}{c}\text { Patients/ } \\
\text { RAND } \\
\text { average } \\
\text { p-value* }\end{array}$ & Spouses & SD & $\begin{array}{c}\text { RAND } \\
\text { average } \neq\end{array}$ & SD & $\begin{array}{l}\text { Spouses/ } \\
\text { RAND } \\
\text { average } \\
\text { p-value* }\end{array}$ & $\begin{array}{l}\text { Patients/ } \\
\text { Spouses } \\
\text { p-value* }\end{array}$ \\
\hline Social functioning & 2 & 82.4 & 22.4 & 77.6 & 5.9 & $<0.001$ & 85.3 & 17.9 & 78.6 & 1.8 & $<0.001$ & 0.261 \\
\hline $\begin{array}{l}\text { Physical } \\
\text { functioning }\end{array}$ & 10 & 81.0 & 21.3 & 68.1 & 10.3 & $<0.001$ & 78.7 & 20.5 & 66.5 & 12.1 & $<0.001$ & 0.176 \\
\hline $\begin{array}{l}\text { Emotional well- } \\
\text { being }\end{array}$ & 5 & 76.0 & 16.3 & 74.5 & 2.6 & 0.028 & 76.0 & 15.1 & 73.7 & 2.0 & 0.007 & 0.938 \\
\hline Bodily pain & 2 & 75.7 & 23.1 & 67.8 & 6.3 & $<0.001$ & 74.0 & 22.9 & 65.9 & 5.1 & $<0.001$ & 0.463 \\
\hline $\begin{array}{l}\text { Role } \\
\text { functioning/emoti } \\
\text { onal }\end{array}$ & 3 & 69.8 & 39.0 & 63.5 & 10.4 & 0.032 & 73.1 & 35.8 & 63.8 & 8.5 & $<0.001$ & 0.267 \\
\hline Energy & 4 & 67.5 & 21.1 & 62.7 & 5.8 & $<0.001$ & 68.1 & 18.8 & 59.8 & 3.6 & $<0.001$ & 0.956 \\
\hline $\begin{array}{l}\text { Role } \\
\text { functioning/physi } \\
\text { cal }\end{array}$ & 4 & 65.6 & 40.9 & 54.7 & 12.3 & 0.003 & 70.4 & 37.2 & 54.1 & 13.0 & $<0.001$ & 0.173 \\
\hline General health & 5 & 59.1 & 17.8 & 50.6 & 4.6 & $<0.001$ & 61.6 & 17.7 & 52.8 & 6.3 & $<0.001$ & 0.156 \\
\hline
\end{tabular}

${ }^{\dagger}$ Scale: 0: poor health and quality of life - 100: good health and quality of life

₹ Age-stratified general male / female populations (16)

* Wilcoxon Signed Ranks test

Significant $\mathrm{P}$ value in boldface $(\mathrm{P}<0.05)$. 
Table 3. Association between the demographic characteristics of patients with prostate cancer ( $\mathrm{n}=232$ ) and their HRQOL (RAND-36)

\begin{tabular}{|c|c|c|c|c|c|c|c|c|}
\hline \multirow{3}{*}{ Variable } & \multirow[t]{2}{*}{$\begin{array}{l}\text { Physical } \\
\text { functioning } \\
\qquad \mathrm{M}(\mathrm{SD})\end{array}$} & \multirow{3}{*}{$\begin{array}{l}\text { Role } \\
\text { functioning/ } \\
\text { physical } \\
\text { p-value }\end{array}$} & \multirow{2}{*}{$\begin{array}{l}\text { Role } \\
\text { functioning/ } \\
\text { emotional } \\
\qquad \text { M (SD) }\end{array}$} & \multirow{3}{*}{$\begin{array}{l}\text { Energy } \\
\text { p-value }^{M(S D)}\end{array}$} & \multirow{2}{*}{$\begin{array}{l}\text { Emotional } \\
\text { well-being } \\
\text { M (SD) }\end{array}$} & \multirow{3}{*}{$\begin{array}{l}\text { Social } \\
\text { functioning } \\
\qquad \mathrm{M}(\mathrm{SD}) \\
\text { p-value }\end{array}$} & \multirow[t]{2}{*}{$\begin{array}{l}\text { Bodily pain } \\
\qquad \mathrm{M}(\mathrm{SD})\end{array}$} & \multirow[t]{2}{*}{$\begin{array}{l}\text { General health } \\
\text { M (SD) }\end{array}$} \\
\hline & & & & & & & & \\
\hline & p-value & & p-value & & $\mathrm{p}$-value & & p-value & $\mathrm{p}$-value \\
\hline Age years & $<0.001$ & $<0.001$ & 0.117 & 0.005 & 0.056 & 0.086 & 0.059 & 0.012 \\
\hline$\leq 59$ & $80.6(24.7)$ & $63.4(41.9)$ & $65.0(42.1)$ & $60.0(23.0)$ & 70.5 (18.8) & $78.0(27.8)$ & $70.2(27.9)$ & $60.9(19.0)$ \\
\hline $60-69$ & $86.9(15.6)$ & $78.9(34.9)$ & $77.0(34.1)$ & $72.6(17.6)$ & $77.8(15.9)$ & $86.6(18.0)$ & $80.2(20.2)$ & $62.3(16.8)$ \\
\hline$\geq 70$ & $74.6(23.4)$ & $52.2(42.4)$ & $64.0(41.6)$ & $65.5(22.6)$ & $76.6(15.0)$ & $79.9(23.6)$ & $73.3(23.1)$ & $54.7(17.9)$ \\
\hline Other disease & $<0.001$ & 0.010 & 0.108 & 0.114 & 0.026 & 0.055 & 0.003 & $<0.001$ \\
\hline Yes & $77.4(22.6)$ & $60.5(42.6)$ & $66.9(40.3)$ & $65.8(22.1)$ & $74.2(17.0)$ & $80.6(23.2)$ & $72.6(24.4)$ & $55.4(18.2)$ \\
\hline No & $88.6(16.0)$ & $76.7(34.7)$ & $75.9(35.5)$ & $71.2(18.4)$ & 79.8 (13.9) & $86.3(20.2)$ & $82.5(18.6)$ & $67.0(14.2)$ \\
\hline Treatment method & 0.015 & 0.009 & 0.103 & 0.131 & 0.350 & 0.009 & 0.018 & $<0.001$ \\
\hline Surgery & $83.4(19.8)$ & $73.8(38.6)$ & $76.0(37.6)$ & $71.6(17.3)$ & $78.6(14.5)$ & $83.8(21.8)$ & $79.0(20.2)$ & $66.7(15.7)$ \\
\hline Radiation therapy & $84.7(15.4)$ & $60.2(37.5)$ & $65.6(40.1)$ & $68.8(21.2)$ & $75.1(15.8)$ & $82.4(20.8)$ & $79.7(18.7)$ & $60.9(15.3)$ \\
\hline Hormonal treatment & $71.1(26.2)$ & $50.5(45.0)$ & $59.3(41.7)$ & $59.7(24.4)$ & $72.5(17.8)$ & $73.5(25.2)$ & $64.6(26.9)$ & $49.0(17.5)$ \\
\hline Non-invasive care & $83.3(19.9)$ & $70.6(39.2)$ & $72.6(37.7)$ & $68.3(20.6)$ & $76.0(16.8)$ & $86.3(21.0)$ & $77.8(23.1)$ & $58.5(18.1)$ \\
\hline
\end{tabular}


Table 4. Association between the demographic characteristics of spouses ( $n=229)$ and their HRQOL (RAND-36)

\begin{tabular}{|c|c|c|c|c|c|c|c|c|}
\hline \multirow{3}{*}{ Variable } & $\begin{array}{l}\text { Physical } \\
\text { functioning }\end{array}$ & $\begin{array}{l}\text { Role functioning/ } \\
\text { physical }\end{array}$ & \multirow{2}{*}{$\begin{array}{l}\text { Role functioning/ } \\
\text { emotional } \\
\qquad M(\mathrm{SD})\end{array}$} & \multirow{2}{*}{$\begin{array}{l}\text { Energy } \\
\qquad \mathrm{M}(\mathrm{SD})\end{array}$} & \multirow{3}{*}{$\begin{array}{l}\text { Emotional } \\
\text { well-being } \\
\text { M (SD) } \\
\text { p-value }\end{array}$} & \multirow{2}{*}{$\begin{array}{l}\text { Social } \\
\text { functioning } \\
\qquad M(\mathrm{SD})\end{array}$} & \multirow{2}{*}{$\begin{array}{l}\text { Bodily pain } \\
\qquad \mathrm{M}(\mathrm{SD})\end{array}$} & \multirow{3}{*}{$\begin{array}{l}\text { General health } \\
\text { M (SD) }\end{array}$} \\
\hline & $\mathrm{M}(\mathrm{SD})$ & $\mathrm{M}(\mathrm{SD})$ & & & & & & \\
\hline & p-value & p-value & p-value & p-value & & p-value & p-value & \\
\hline Age years & $<0.001$ & $<0.001$ & $<0.001$ & 0.109 & 0.336 & 0.134 & 0.119 & $<0.001$ \\
\hline$\leq 59$ & $86.2(16.8)$ & $85.7(25.9)$ & $80.8(30.5)$ & $64.5(21.2)$ & $74.2(16.0)$ & $84.8(18.3)$ & $76.5(21.8)$ & $68.3(18.2)$ \\
\hline $60-69$ & $80.3(19.4)$ & $72.0(37.3)$ & $81.5(31.8)$ & $71.1(17.1)$ & $77.6(14.9)$ & $87.9(16.0)$ & $75.9(21.7)$ & $62.9(17.4)$ \\
\hline$\geq 70$ & $70.4(22.4)$ & $55.5(40.2)$ & $55.8(40.7)$ & $70.0(17.9)$ & $75.1(14.6)$ & $81.8(19.7)$ & $69.5(24.9)$ & $54.8(15.3)$ \\
\hline Basic education & 0.001 & 0.122 & 0.004 & 0.529 & 0.957 & 0.347 & 0.106 & $<0.001$ \\
\hline Elementary/civic school & $75.0(20.6)$ & $64.9(39.6)$ & $65.7(38.7)$ & $70.1(17.1)$ & $75.8(15.8)$ & $84.1(18.0)$ & $72.4(22.8)$ & $57.8(16.3)$ \\
\hline $\begin{array}{l}\text { Comprehensive/lower } \\
\text { secondary school }\end{array}$ & $79.9(20.8)$ & $73.4(35.0)$ & $79.8(33.5)$ & $66.5(19.7)$ & $75.9(14.0)$ & $85.9(17.9)$ & $72.3(24.3)$ & $61.1(18.4)$ \\
\hline Upper secondary school & $85.3(18.5)$ & $78.0(33.2)$ & $82.5(30.5)$ & $66.4(20.1)$ & $76.3(15.1)$ & $86.9(17.4)$ & $79.4(20.4)$ & $69.3(16.9)$ \\
\hline Vocational qualifications & 0.004 & 0.220 & 0.057 & 0.925 & 0.357 & 0.095 & 0.049 & $<0.001$ \\
\hline Initial vocational qualification & $75.9(19.8)$ & $65.4(37.2)$ & $72.8(36.7)$ & $67.8(17.9)$ & $75.5(15.5)$ & $84.2(17.0)$ & $70.1(23.7)$ & $58.6(18.0)$ \\
\hline $\begin{array}{l}\text { Further vocational } \\
\text { qualification }\end{array}$ & $81.6(21.7)$ & $73.9(35.7)$ & $78.4(34.3)$ & $68.3(18.6)$ & $76.6(14.4)$ & $85.4(18.1)$ & $75.0(24.1)$ & $65.2(17.6)$ \\
\hline Polytechnic/university degree & $87.0(15.5)$ & $81.7(30.0)$ & $84.4(31.2)$ & $67.3(20.9)$ & $78.7(14.6)$ & $90.8(16.1)$ & $83.3(16.8)$ & $71.0(15.8)$ \\
\hline No vocational qualification & $75.6(21.6)$ & $68.1(41.0)$ & $66.7(37.1)$ & $67.4(19.2)$ & $73.5(16.4)$ & $82.6(19.5)$ & $72.3(22.3)$ & $56.6(16.3)$ \\
\hline Chronic diseases & $<0.001$ & $<0.001$ & 0.006 & 0.025 & 0.363 & 0.001 & $<0.001$ & $<0.001$ \\
\hline Yes & $74.0(21.9)$ & $60.8(39.5)$ & $69.2(37.5)$ & $66.1(19.3)$ & $75.2(15.6)$ & $82.4(19.1)$ & $68.5(23.5)$ & $56.9(16.7)$ \\
\hline No & $88.0(13.8)$ & $88.0(24.1)$ & $82.3(31.7)$ & $71.8(16.9)$ & $77.3(14.1)$ & $90.4(13.9)$ & $84.4(17.4)$ & $70.3(16.0)$ \\
\hline
\end{tabular}

The p-values in boldface have been adjusted according to the Bonferroni correction. 